\title{
Implementação de um aplicativo móvel (App) para leitura de medidores de água e energia baseado em visão computacional
}

\section{Implementation of a meter reading mobile application (App) for water and electricity based on computational vision}

\author{
Alberto José Alvares ${ }^{\oplus}, 1$, Ana Carolina Alves Souza ${ }^{1}$, Matheus Feitosa de \\ Castro $^{1}$ \\ ${ }^{1}$ Universidade de Brasília (UnB), Departamento Eng. Mecânica (EnM), Brasil \\ *alvares@AlvaresTech.com; acarolina.eng@gmail.com; matheusfk74@gmail.com
}

Recebido: 04/02/2020. Revisado: 25/07/2020. Aceito: 24/09/2020.

\begin{abstract}
Resumo
Este trabalho apresenta um novo método baseado em visão computacional para automatizar o processo de leitura de medidores de água (hidrômetros), medidores de gás e medidores de eletricidade, com visor analógico ou digital, por meio de uma aplicação móvel (App), plataforma iOS e Android, utilizando visão computacional e Rede Neural Convolucional para adquirir os dígitos exibidos no visor do medidor de consumo de água, gás e energia (leitura de consumo centrada no consumidor, Autoleitura) e seu armazenamento na nuvem em um banco de dados NoSQL para análise preditiva futura (Big Data). O artigo aborda a arquitetura e o desenvolvimento do aplicativo para ser usado nas empresas concessionárias de energia e água de Brasília, CEB (Companhia Energética de Brasília) e CAESB (Companhia de Saneamento Ambiental do Distrito Federal).
\end{abstract}

Palavras-Chave: Aprendizagem de Máquina; Autoleitura; Medidor de Água; Medidor de Eletricidade; Visão Computacional

\section{Abstract}

This work presents a new method based on computer vision to automate the process of reading water meters (hydrometers), gas meters and electricity meters, with analog or digital display, through a Mobile Application (App), iOS and Android platform, making use of computer vision to acquire the digits displayed on the meter display of water and energy consumption (consumption reading) and its cloud storage in a NoSQL database for future predictive analysis (Big Data). This article will address the architecture and development of the Computer Vision-based App developed to be used in the energy and water concessionaires of Brasília, CEB (Companhia Energética de Brasília) and CAESB (Companhia de Saneamento Ambiental do Distrito Federal).

Keywords: Computer Vision; Electricity Meter; Internet of Things; Machine Learning; Water Meter

\section{Introdução}

Este artigo apresenta a concepção de um novo método para automação do processo de leitura de medidores de vazão (hidrômetros) e de eletricidade, com mostradores analógico ou digital, implementado em uma aplicação móvel (App), plataformas iOS e Android, fazendo uso de visão computacional e inteligência artificial, apren- 
dizagem de máquina para reconhecimento automático dos dígitos exibidos no mostrador dos medidores, automatizando o procedimento de leitura, sendo centrado no cliente, ou seja, o cliente que possui um medidor de água ou eletricidade realiza a medição.

Empresas de distribuição e saneamento de água no Brasil como a CAESB, tem um índice de perdas na distribuição de água de 34,49\% em 2018 (CAESB, 2019). Estas empresas tem um problema a ser resolvido a fim de diminuir a perda na distribuição, pois usam um sistema de medição manual de leitura, e no caso da CAESB são feitas leituras manuais uma vez por mês de 710 mil medidores, tendo um custo de cerca de 6 milhões de reais por ano com o procedimento de medição manual, leiturista, com pagamento de uma leitura por mês, que custa cerca de 70 centavos/hidrômetro.

Segundo estudos realizados pela CAESB (CAESB, 2019) se o processo for automatizado com medição on-line dos hidrômetros ou por algum outro método, que disponibilize as leituras diversas vezes por dia, poder-se-ia reduzir a perda na distribuição para cerca de $12 \%$, além de economizar com o custo da leitura manual mensal de cada hidrômetro, representando uma economia de mais de 6 milhões de reais por ano, só com custos associados ao leiturista. 0 método descrito neste artigo irá atender esta necessidade da empresa citada e de similares de forma inteligente, não invasiva, sustentável e aderente aos conceitos de Internet das Coisas e Indústria 4.0 (Alcácer and Cruz-Machado, 2019).

O desenvolvimento tem por finalidade automatizar a leitura de medidores de água, gás e/ou eletricidade, transferindo a medição manual realizada pela concessionária de água/energia/gás para o usuário final/consumidor (medição centrada no consumidor), tendo sido implementada em Brasília atendendo às empresas CEB (Companhia Energética de Brasília) e CAESB (Companhia de Aguá e Esgoto de Brasília).

A App concebida para reconhecimento de dígitos de medidores analógicos foi treinada usando os modelos de medidores de eletricidade e água utilizados no Distrito Federal, podendo diferir de outros modelos utilizados em outras localidades. Cada medidor analógico necessita de um treinamento específico por parte da App para fazer o reconhecimento de dígitos com alta eficiência, exatidão da ordem de $98 \%$ (Cerman et al., 2016).

O método concebido é baseado em visão computacional e aprendizagem de máquina usando um dispositivo móvel como um celular/smartphone ou tablet com conexão à Internet via Wi-Fi ou conexão de dados por GSM/GPRS/Edge/3G/4G/5G, não necessitando que seja realizada a troca dos medidores analógicos utilizados nos estabelecimentos comerciais e residenciais, sendo não invasivo podendo ser operado pelo leiturista da empresa prestadora de serviço para concessionária de água/luz/gás/correlatos ou pelo próprio usuário do medidor, hidrômetro ou relógio de luz (cliente final), automatizando o processo de medição usando uma App.

Após concretizar a medição usando a App, o aplicativo móvel envia, para o servidor em nuvem, a leitura (valor da medição), time stamp (data/hora), código de barras com identificação do medidor (Id) e a imagem, apenas se o reconhecimento dos dígitos for validado pelo operador da App. O servidor na nuvem será o responsável pelo processamento dos dados armazenados e a gestão do medidor analógico usando técnicas de mineração de dados em um contexto de Internet das Coisas e cidades sustentáveis (Big Data Analytics). A App, usuário final, receberá também informações do servidor em nuvem, sobre consumo, valor da conta e alerta sobre possível vazamento, entre outras informações de realimentação, em um contexto de análise preditiva.

O artigo está organizado em nove seções. A Seção 2 apresenta o problema a ser resolvido com o uso do App. A Seção 3 apresenta uma revisão de literatura baseada em trabalhos correlatos que usam visão computacional. A Seção 4 apresenta a solução proposta centrada no cliente da concessionária de energia ou de água. A Seção 5 apresenta uma oportunidade para o uso da App na CAESB e CEB. A Seção 6 apresenta a arquitetura da solução proposta. A Seção 7 apresenta a modelagem UML da App a ser usada pela CAESB e CEB. A Seção 8 apresenta um estudo de caso da App CAESB e App CEB. A Seção 9 apresenta a conclusão e trabalhos futuros.

\section{O Problema Hídrico no Distrito Federal e o Impacto da Medição Online}

No caso de distribuição de água, empresas como a CAESB poderão diminuir a perda na distribuição em cerca de $22 \%$ se todos os hidrômetros de Brasília disponibilizarem as medições de consumo, formando a Internet dos Hidrômetros, através dos usuários conectados via App publicando mais de uma leitura de medição por dia do seu consumo de água (Santiago and Alvares, 2017), como se a medição fosse online. Segundo a CAESB (CAESB, 2019) o ideal seriam quatro leituras por dia.

Como o universo de medidores de água é da ordem de 710 mil em Brasília/Distrito Federal (DF) e mais de 40 milhões no Brasil, a App tem um universo de potenciais usuários significativo tanto no Brasil quanto na América Latina, só levando em conta a Internet de Hidrômetros, que é um dos focos deste desenvolvimento.

O Distrito Federal entre 2017-2018 enfrentou uma crise hídrica sem precedentes, comprometendo o abastecimento de água. A CAESB foi obrigada a implantar uma política de racionamento de água em todo DF, onde cada região permaneceu 24 horas sem água durante a semana em 2018, visando uma redução drástica do consumo para mitigar a pequena quantidade de água armazenada em seus reservatórios.

Vários produtos de mercado (Weranga et al., 2014) se propõem a resolver o problema associado à automação da medição e transmissão de dados, em tempo real, passando pelo uso de coletores de dados até o uso de medidores automáticos, sendo denominados de medidores inteligentes (SMT, Smart Metering Technology) (Chouiten and Schaeffer, 2014, Toledo, 2013, Alvisi et al., 2019).

Em setembro de 2019 a CAESB iniciou um teste piloto usando 1430 medidores inteligentes ao custo de 
dois milhões e meio de reais. Entretanto, este tipo de solução é muito cara em comparação com a solução manual usando leituristas, pois o custo de 1 leitura mensal sai por cerca de 70 centavos, o que é muito barato quando comparado com um método de automação da medição online dos hidrômetros por rádio frequência ou GPRS (dados celulares), medidores inteligentes. Em função desta constatação a medição online para todos os 710 mil hidrômetros do DF foi descartada pela CAESB, sendo realizado apenas testes pilotos usando tecnologia LoRaWAN (Low Power WAN Protocol for Internet-of-Things) (Seneviratne, 2019).

De acordo com Nardo et al. (2013) vazamentos de água podem ser divididos em perdas reais, que é a água realmente perdida ao entregar o serviço, e perdas aparentes, consumo não autorizado (furtado), ou seja, água entregue aos consumidores mas não faturado.

O gerenciamento de vazamentos envolve quatro atividades: avaliação, detecção, redução de perdas e monitoramento. O monitoramento do consumo é muito importante para gestão da distribuição de água e eletricidade impactando diretamente a rentabilidade da empresa e o meio ambiente (Pattinson, 2015). O uso da App poderá de fato melhorar a gestão da água e energia elétrica no DF.

\section{Trabalhos Correlatos}

Alvares and Santiago (2020) apresentam a concepção de um novo método desenvolvido em Python para automatizar o processo de leitura de hidrômetros com visor analógico usando visão computacional e aprendizado de máquina. Uma câmera captura o valor do consumo no hidrômetro e a imagem produzida passa pelo processamento de visão computacional até que os dígitos sejam detectados e isolados. Em seguida, os dígitos são passados para três modelos de aprendizado de máquina: SVM (Support Vector Machine), KNN (k-Nearest Neighbor) e Rede Neural Artificial. Cada modelo realiza a função de OCR (Optical Character Recognition) de alta precisão. No geral, as três médias de exatidão calculadas sugerem que o SVM é o melhor dos três modelos, com uma taxa de sucesso de reconhecimento de $99,4 \%$ (exatidão). Atrás, a segunda melhor taxa foi encontrada com KNN $(98,3 \%)$ e a terceira com Rede Neural Perceptron (97,6\%). O software é executado em plataforma Raspberry Pi usando o sistema operacional Linux. Este trabalho apresenta uma extensa revisão de literatura sobre medidores inteligentes.

Elrefaei et al. (2015) apresentam um sistema baseado no processamento de imagens para obter uma leitura eficiente e precisa do medidor digital de eletricidade implementado com Android Studio e biblioteca openCV sendo testado em 21 imagens de medidores elétricos usados na Arábia Saudita, capturadas pela câmera de Smartphone. Os resultados mostram um reconhecimento com uma taxa de precisão de $96,49 \%$ (por dígito numérico) e taxa de precisão de $85,71 \%$ para as leituras do medidor de eletricidade testado.

Sonali et al. (2015) apresentam uma proposta de arquitetura para leitura de medidores de energia e água usando OCR em plataforma Android, sem contudo apresentar detalhes da implementação e nem dos resultados obtidos. O aplicativo foi projetado basicamente para reduzir o trabalho tedioso e evitar os erros humanos.

Spichkova et al. (2019) relatam que o uso de medidores inteligentes, Smart Meters, é uma solução cara e requer a substituição dos medidores existentes, mesmo quando funcionais, e grandes mudanças de todo o sistema que lidam com as leituras do medidor são necessárias. Apresentam os resultados de um projeto de automação do processo de leitura de medidores para medidores padrão (não inteligentes) usando visão computacional, com foco na comparação de duas técnicas de visão computacional na nuvem, Google Cloud Vision e AWS (Amazon Web Service) Rekognition. Um Aplicativo móvel captura a imagem do mostrador do medidor e envia para o serviço de visão computacional na nuvem, Google e Amazon, que faz o reconhecimento dos dígitos da leitura.

No trabalho produzido por Auerswald (2017) o OCR criado é destinado a reconhecer dígitos de instrumentos de medição que possuam display de sete segmentos.

Cerman et al. (2016) criaram um App baseado em visão computacional capaz de escanear medidores de eletricidade, gás e água. A metodologia compreende dois estágios: detecção de dígitos e reconhecimento óptico de caracteres. Um pipeline de operações realiza a detecção de dígitos. O OCR é conseguido empregando duas abordagens diferentes: Tesseract OCR (Smith, 2007) e Rede Neural Convolucional (CNN). A Rede Neural Convolucional supera significativamente o OCR Tesseract para todos os tipos de medidores analisados.

Segundo Tafti et al. (2016) um conjunto de diferentes plataformas de OCR estão agora disponíveis e o trabalho apresenta várias avaliações experimentais qualitativas e quantitativas que foram realizadas usando quatro serviços de OCR bem conhecidos: OCR Tesseract, ABBYY FineReader, Transym e Google Docs OCR.

A empresa Waterloo, Austria, já disponibiliza uma App para diversas cidades, incluindo Alemanha, para auxiliar na automação da leitura e gestão de consumo de água (https://tinyurl. com/w5mgl4z).

Sun et al. (2016) fazem uma revisão sistemática do desenvolvimento e implantação de medidores inteligentes (Smart Meters), incluindo medidores inteligentes de eletricidade, de calor e de gás. Os medidores inteligentes são dispositivos eletrônicos que medem o consumo de energia elétrica, por exemplo, e operam a comunicação bidirecional em relação às informações de consumo de energia e faturamento e o status das redes de energia (smart grid).

Gallo et al. (2015) propuseram uma solução de automação da medição de gás por meio de visão computacional sendo usada pelo leiturista a fim de reduzir chances de erro humano de leitura.

Puttnies et al. (2015) tentam resolver a questão contemporânea de integrar dispositivos convencionais no contexto da Internet das Coisas. Mais especificamente, encarram o desafio de transformar um medidor de eletricidade analógico em um digital, inteligente, capaz de se conectar à Internet e usar serviços de rede para fornecer uma leitura remota. A maneira proposta de 
solucionar esse problema é utilizando a visão computacional para identificar e extrair a indicação do visor dos medidores de eletricidade, gás e água.

LeCun et al. (2015) apresentam uma revisão de literatura sobre aprendizado de máquina aplicado ao processamento de imagens e visão computacional. Em sua investigação, o desenvolvimento de uma solução de aprendizado de máquina para classificação de dígitos de sistemas de medição analógicos, com visores digitais ou analógicos, usando algoritmos de aprendizado supervisionado. Para resolver o problema, concentram em três algoritmos diferentes: KNN, SVN e rede neural.

A abordagem introduzida por Chouiten and Schaeffer (2014) trabalha com 5 modelos de medidores de gás, que são empregados pelo principal fornecedor de gás na França, ENGIE. Os experimentos são realizados por 16 modelos de smartphones em plataforma Android e 4 modelos de smartphones com plataforma iOS.

Vanetti et al. (2013) apresentam uma abordagem para a leitura automática de medidores de gás através de visão computacional. A leitura do medidor de gás, geralmente feita no local por um operador que tira uma foto como prova de leitura, caso necessário posteriormente, é propensa a erros. Neste estudo, os autores apresentam um método para apoiar o processo de validação para reduzir o esforço humano. Seu algoritmo é treinado para detectar e reconhecer o texto de uma região de interesse específica (ROI). Primeiro, eles detectam o ROI e segmentam o texto contido nele, usando um método baseado em um conjunto de modelos de redes neurais. Em seguida, eles executam um reconhecimento óptico de caracteres usando SVN.

O método criado por Oliveira (2013) reconhece os caracteres de um tipo específico de medidor elétrico (M1A-T), utilizado no Brasil. O algoritmo compreende três etapas principais, processando imagens de entrada de tamanho e formato fixos. Em primeiro lugar, o filtro homomórfico é aplicado para reduzir os efeitos da iluminação não uniforme. Em segundo lugar, operações de binarização e morfológicas são realizadas para obter o ROI e os dígitos separados. Em terceiro lugar, os dígitos segmentados são classificados pelo algoritmo kNN.

Kompf (2013) apresenta um desenvolvimento de software de OCR para medidores de eletricidade, no qual o código do computador foi escrito em $\mathrm{C}++$, utilizando OpenCV.

Bae et al. (2005) apresentam um sistema de reconhecimento de caracteres baseado em câmera, que é implementado para dispositivos móveis, como PDA (Personal Device Assistance) e telefones celulares com câmeras.

Zhao et al. (2005) introduzem um método projetando a arquitetura de um sistema de medição remota que pode ler um medidor de energia através de visão computacional. Diferentemente do sistema típico de medição automática que deve obter o valor de consumo através de uma interface de comunicação digital com o medidor, o método proposto reconhece a leitura do medidor utilizando técnicas de visão computacional, que configuram um modo de medição sem contato. No trabalho, as informações de medição local das subestações distribuídas são transmitidas para uma estação central através de uma rede de computadores. Em um experimento realizado, os resultados da visão computacional são precisos o suficiente para monitorar os parâmetros de operação da subestação remota.

O uso de App na automação da leitura de medidores baseado em visão computacional é recente e não se tem notícia do seu uso no Brasil e de nenhum outro desenvolvimento no Brasil neste contexto. A Autoleitura automatizada apresenta três vantagens na sua adoção: economia de tempo e dinheiro; precisão e rapidez; e otimização do fluxo de trabalho por parte da empresa que realiza a leitura manual ou mesmo por parte do consumidor final que usa a App.

Pelandiana and Ado (2018) descrevem o desenvolvimento de um sistema de cobrança e leitura baseado na Web para uma unidade municipal de água e serviços nas Filipinas, que procurou resolver o problema de gestão municipal de água usando tecnologia da informação, onde a leitura do medidor é digital usando SMart Meters.

Mendes et al. (2020) descrevem um método de Autoleitura desenvolvido para a empresa Equatorial Energia usando reconhecimento de dígitos de medidores de energia por meio da voz, via processamento de áudio e inteligência computacional, no contexto de um Aplicativo.

Este trabalho inspirou-se principalmente nas referências de Alvares and Santiago (2020) e Cerman et al. (2016). Maiores detalhes sobre o fluxo de dados pra OCR podem ser obtidos em Alvares and Santiago (2020) e o uso de um kernel OCR para App usando Rede Neural Convolucional em Cerman et al. (2016). O trabalho contribui com uma nova arquitetura visando a automação da leitura de medidores de água, energia e gás centrada no cliente usando um App através de visão computacional, Rede Neural Convolucional, banco de dados em nuvem e análise preditiva, viabilizando a Autoleitura automatizada.

A Tabela 1 apresenta uma comparação dos métodos de visão computacional relatados na revisão de literatura, bem como do método proposto neste trabalho (SmartTelemetria).

\section{Leitura de Medidores Centrada no Usuá- rio}

O método proposto permite que o consumidor final continue a utilizar o seu medidor com mostrador analógico ou digital, não sendo necessário a intervenção para remoção e instalação de um novo medidor inteligente com módulo de medição automática e comunicação online.

O medidor analógico já instalado poderá continuar a ser usado, minimizando custos de implantação da solução de automação proposta baseada em App. Este é um requisito importante para concepção do princípio de solução, pois irá concentrar o desenvolvimento em uma solução não invasiva, sem troca de medidor e usando visão computacional num contexto de Internet das Coisas (IoT) e Indústria 4.0 (Alcácer and Cruz-Machado, 2019). A solução será centrada no cliente final da con- 
Tabela 1: Comparação entre os métodos relatados na literatura e o proposto, denominado de SmartTelemetria

\begin{tabular}{|c|c|c|c|c|c|}
\hline Solução OCR & Método & Aplicação & OCR Nuvem/App & Genérico & Exatidão \\
\hline Alvares and Santiago (2020) & OpenCV e Rede Neural & Água & Raspberry & Não & $\approx 95 \%$ \\
\hline Elrefaei et al. (2015) & OpenCV & Energia & Android & Não & $\approx 86 \%$ \\
\hline Spichkova et al. (2019) & Google e Amazon & Água & Cloud & Não & $\approx 50 \%$ \\
\hline Auerswald (2017) & OpenCV e Rede Neural & Água & Raspberry & Não & $\approx 95 \%$ \\
\hline Cerman et al. (2016) & CNN e Tesseract & Água, Energia e Gás & Android e iOS & Sim & $\approx 97 \%$ \\
\hline Gallo et al. (2015) & Tesseract & Gás & Android & Não & $\approx 85 \%$ \\
\hline Chouiten and Schaeffer (2014) & Tesseract & Gás & Android & Não & $\approx 85 \%$ \\
\hline Vanetti et al. (2013) & SVN & Gás & Android & Não & $\approx 90 \%$ \\
\hline Oliveira (2013) & KNN & Energia & Android & Não & $\approx 90 \%$ \\
\hline Kompf (2013) & OpenCV & Energia & Raspberry & Não & $\approx 90 \%$ \\
\hline Zhao et al. (2005) & OpenCV & Energia & Desktop & Não & $\approx 90 \%$ \\
\hline Proposta SmartTelemetria & CNN & Água, Energia, Gás & Android e iOS & Sim & $\approx 97 \%$ \\
\hline
\end{tabular}

cessionária de água e eletricidade, que poderá realizar a medição através de uma leitura do visor de forma automatizada sendo o resultado armazenado em um banco de dados na nuvem.

O mesmo cenário pode ser destacado para os medidores de eletricidade, pois cada residência e estabelecimento comercial possui pelo menos dois medidores, eletricidade e água. Algumas cidades também tem medidores de gás.

Assim sendo, com o apoio da medição assistida pela App, de forma simples e rápida, todas as leituras dos medidores podem ser disponibilizadas às concessionárias do serviço de distribuição de água, gás e eletricidade visando a gestão dos ativos e uso racional da água, gás e eletricidade.

O método proposto baseado em uso de App, visão computacional e Rede Neural Convolucional tem como principal premissa a possibilidade de realizar a medição centrada no consumidor, com custo muito baixo e sem a necessidade de vultosos investimentos para implantação de medidores inteligentes.

Estima-se que a CAESB teria um gasto da ordem de um bilhão de reais para implantar uma rede de 710 mil medidores inteligentes baseados na tecnologia LoRaWan (CAESB, 2019) para realizar quatro medições por dia, o que inviabiliza o uso generalizado da tecnologia de medidores inteligentes.

\section{Oportunidade Uso App Automação Lei- tura de Medidores}

A popularização do uso de smartphones no Brasil e no mundo aliado ao seu poder de processamento e recursos como câmeras digitais de alta resolução permite que o celular seja utilizado para auxiliar a automação do procedimento de medição de medidores de água, eletricidade e gás.

A grande vantagem do uso de uma App (Aplicação) para plataforma móvel, como Android e iOS, é permitir a automação da leitura do medidor e disponibilização dos dados em nuvem tendo um custo extremamente baixo, pois não é necessário a troca do medidor por uma solução automatizada baseada em hardware/software de leitura; e permite que os dados armazenados na nuvem possam ser utilizados na gestão da distribuição de eletricidade e/ou água pela companhia que presta o serviço, no caso em tela CEB e CAESB, para detecção de vazamentos, gestão hídrica e elétrica, ou seja, usando inteligência artificial visando análise preditiva (Big Data Analytics) dos dados disponibilizados pelos usuários. O usuário poderá também acompanhar o seu consumo diário pois tem acesso ao histórico das leituras no próprio celular.

Assim, o método em questão adere à Internet das Coisas e à Computação em Nuvem (Alcácer and CruzMachado, 2019) aplicada à leitura automática de medidores em geral, como água e eletricidade, mais usuais (Indústria 4.0), tendo as seguintes metas associadas:

- Desenvolvimento de App para Android e iOS para leitura automática de medidores analógicos e digitais baseada em visão computacional (aquisição imagem, processamento da imagem, detecção da região de interesse que contem os dígitos, segmentação dos vários dígitos presentes no visor), para posterior reconhecimento de padrões com processamento local no celular;

- Treinamento dos algoritmos baseado em aprendizagem de máquina usando Redes Neurais Convolucionais (Cerman et al., 2016) para reconhecer os dígitos de várias famílias de hidrômetros, medidores de eletricidade e medidores de gás com baixo erro, exatidão da ordem de 99,34\%;

- Testes reais da App usando os diferentes tipos de hidrômetros usados em campo pela CAESB e medidores de eletricidade usados pela CEB;

- Desenvolvimento dos servidores em nuvem, banco de dados NoSQL (Firebase) fazendo o armazenamento dos dados de leitura dos usuários final (identificação do cliente/residência/comércio) via NoSQL, no banco de dados dos Hidrômetros/Eletricidade/Gás, bem como o desenvolvimento do software de mineração de dados usando técnicas de inteligência artificial de forma escalonável através de soluções de armazenamento e processamento como o sistema Watson da IBM e serviços similares da Microsoft e Google;

- Integração e testes da App com servidores em nuvem, armazenamento e gestão sustentável do uso e distribuição de água com detecção de vazamento e geração de alertas para o usuário final, bem como uma gestão 
inteligente dos sistemas de bombeamento e distribuição de água da CAESB em função do conhecimento do consumo diário das residências/comércio/indústria.

Há varias possibilidades de modelos de negócio associados ao serviço de automação da leitura de medidores usando App. A primeira opção é a cobrança de uma taxa de gestão e detecção de vazamento do cliente final que usar e licenciar a App. A segunda é o uso da App pelas empresas que realizam a leitura dos hidrômetros da concessionária (Pattinson, 2015). A terceira é o uso pela concessionária do banco de dados de usuários da App, disponibilizando uma valiosa informação sobre o consumo diário das residências/comércio/indústria o que irá permitir uma gestão sustentável e eficiente do uso do recurso.

\section{Método Proposto Baseado em App}

O método baseado em visão computacional e aprendizagem de máquina usando um dispositivo móvel como um smartphone ou tablet com conexão à Internet via Wi-Fi ou conexão de dados por GSM/GPRS/Edge/3G/4G/5G pode ser operado pelo leiturista da empresa prestadora de serviço para concessionária de água/luz/gás/correlatos ou pelo próprio usuário do hidrômetro (cliente final), de forma automatizada usando a App que enviará a leitura (valor da medição), time stamp (data/hora), identificação (Id) Medidor (código de barras ou código QR com Id se houver na imagem) e a imagem; após validação do reconhecimento dos dígitos pelo operador da App, para o servidor em nuvem que fará o processamento e a gestão do dispositivo de medição usando técnicas de mineração de dados.

Após aquisição dos dígitos do medidor analógico através de visão computacional e aprendizagem de máquina usando um algoritmo baseado em Rede Neural Convolucional, realizado por um dispositivo computacional em plataforma ARM, smartphone ou tablet, com câmera digital; a App, software, reconhece os dígitos apresentados no visor do medidor (valor medido digitalizado) e mostra o valor digitalizado pro usuário validar a leitura.

Com o dado de consumo digitalizado confirmado pelo usuário da App, é feito o armazenamento em base de dados local e remota gravando o Id (identificação) do dispositivo, a data do evento (time stamp), o valor consumo digitalizado e a imagem do visor do medidor. A seguir a App faz a publicação/transmissão destas informações via Internet podendo usar uma rede virtual privada (VPN) via conexão Wi-Fi ou modem de telefonia celular, com o servidor em nuvem da empresa que realiza a supervisão dos dispositivos de medição conectados via Internet.

Com os dados recebidos pelo provedor de serviços em nuvem poder-se-á fazer a gestão de forma automática através da: emissão de faturas de consumo do estabelecimento/cliente; detecção de vazamentos (consumo em relação ao intervalos que os dados são enviados pelo usuário/leiturista do medidor, que pode realizar várias leituras por dia, por exemplo); envio de e-mails e SMS (Short Message Service) para o cliente final co- municando sobre alertas de consumo anormal, envio de fatura, alertas sobre possibilidade de vazamento devido identificação de consumo fora da média histórica, etc.

Outras ações de gestão da base de dados de medidores supervisionados remotamente, apoiado pelo método executado em App sem necessidade de troca dos medidores, poderão ser previstos, fazendo com que as leituras estejam disponíveis mais que uma única vez por mês, ao contrário do modelo atual, usando o leiturista e uma leitura por mês paga, sendo o método proposto mais eficiente que o modelo atual de leitura (leiturista).

O servidor em nuvem armazena os dados da Internet de Medidores (Internet de Hidrômetros, Internet de Relógios de Luz, Internet de Relógio de Gás, Internet de outros Medidores) e realiza o seu processamento através de Big Data Analytics a fim de executar uma gestão inteligente dos medidores em um contexto de cidades sustentáveis, o que irá contribuir de forma inovadora para o monitoramento e controles de perdas nos sistemas de distribuição de água de abastecimento, como no caso da Internet dos Hidrômetros, por exemplo.

O método proposto é inovador e não há nenhum registro de patente de terceiros ou de produto no mercado nacional que faça a automatização da leitura da medição de medidores com indicação analógica/digital usando um smartphone/tablet com uma App que utilize método de visão computacional (OCR) usando algoritmos de processamento de imagens e aprendizagem de máquina para reconhecimentos dos dígitos em mostradores analógicos e digitais; e a transmissão de dados e imagens do mostrador podendo usar também um canal privado VPN (Virtual Private Network).

De acordo com o ilustrado na Fig. 1 o esquemático do método é subdividido em cinco módulos:

- (1) Medidor de consumo de água (hidrômetro), medidor de gás, medidor de eletricidade (medidor de luz) ou outro medidor com visor/mostrador analógico ou digital sem interface/protocolo de comunicação tendo apenas a possibilidade de disponibilizar o acesso à contagem de pulso com sensor de efeito hall ou semelhante, podendo ter também um dispositivo de atuação para permitir o corte do fornecimento de água ou energia elétrica;

- (2) Plataforma computacional baseada em arquitetura ARM, por exemplo, smartphone ou tablet (Android, iOS, outros sistemas operacionais/plataformas) com câmera integrada, modem de telefonia celular GSM/GPRS/EDGE/3G/4G/5G com cartão SIM (Subscriber Identity Module), rede ethernet Wi-Fi, entre outros, que irá executar a App de visão computacional com aprendizagem de máquina baseada em Rede Neural Convolucional;

- (2 e 3) App, software de captura de imagens, processamento OCR com reconhecimento de dígitos e de código de barras ou QR, armazenamento e publicação das imagens, leitura medição, time stamp e Id do medidor (código de barras ou código $\mathrm{QR}$ ), via TCP/IP, possibilidade de estabelecimento de Rede Virtual Privada (VPN) com servidor remoto em nuvem, além do armazenamento dos eventos de forma 


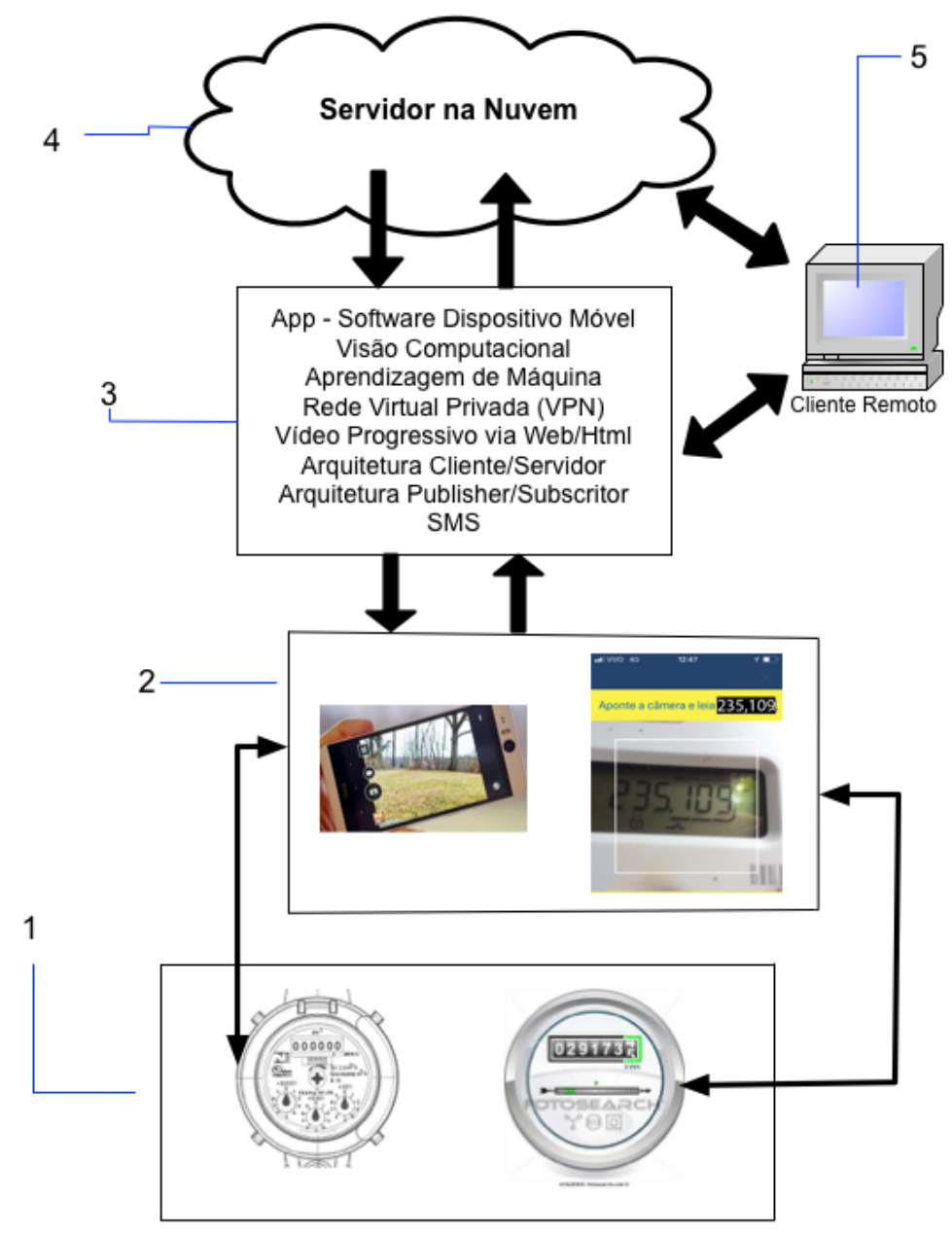

Figura 1: Solução proposta para automação leitura de medidor baseado em App com visão computacional

local (leitura medição consumo, time stamp, imagem, Id dispositivo), podendo operar através de paradigmas de comunicação Request/Response e/ou Publisher/Subscritor, usando também uma Arquitetura Cliente/Servidor como MQTT (Message Queue Telemetry Transport) (Rayes and Samer, 2016);

- (4) Servidor em Nuvem que realiza o armazenamento das medições obtidas pelo sistema e enviadas via TCP/IP e a gestão dos medidores conectados via Internet (Internet do Medidores de Consumo) ou via SMS, possibilitando a detecção de vazamentos, baseado em consumo fora das faixas esperadas e comunicação ao consumidor final baseada numa análise preditiva de vazamento de água (hidrômetros) evitando desperdício de água, perda de receita e melhorando a gestão para concessionária;

- (2 e 5) Cliente/Usuário via App móvel e/ou Computador/Browser que tem acesso remoto via Internet ao servidor em Nuvem ou recebe notificação via SMS e App.

O objetivo do método é desenvolver uma família de Apps (softwares para Android e iOS) e de servidores em nuvem, usando uma arquitetura Cliente/Servidor e
Publisher/Subscritor, onde o usuário final e/ou leiturista usa um smartphone ou tablet (dispositivo móvel) com câmera e executa a App apontando a câmera para o visor do mostrador digital ou analógico do medidor de água/eletricidade/gás para fazer a leitura automática usando algoritmos de visão computacional e aprendizagem de máquina, Rede Neural Convolucional (Deep Learning), reconhecendo os dígitos e alimentando a base de dados no servidor em nuvem, via Internet com conexão Wi-Fi ou dados de celular.

\subsection{Algoritmo de Reconhecimento de Dígitos}

O reconhecimento de dígitos é realizado em dois estágios - detecção de dígitos e OCR (Cerman et al., 2016). O estágio de detecção de dígitos é um pipeline de filtragem, processamento de histograma, operação limiar e operações morfológicas. No estágio de OCR é usado uma Rede Neural Convolucional (CNN).

$O$ algoritmo de detecção de dígitos pode ser sumarizado nos seguintes passos (Cerman et al., 2016):

- Detecção de fundo preto e branco; 
Tabela 2: Percentual de acerto (Exatidão) na classificação baseada em OCR usando os métodos CNN e Tesseract para medidores de gás, eletricidade e água

\begin{tabular}{|c|c|c|c|c|c|}
\hline Método & Tipo Medidor & Imagens Detectadas & Total Imagens & Exatidão & Média - Exatidão \\
\hline Tesseract & $\begin{array}{l}\text { Gás } \\
\text { Eletricidade } \\
\text { Água }\end{array}$ & $\begin{array}{c}6161 \\
25633 \\
2669\end{array}$ & $\begin{array}{c}7558 \\
29474 \\
3150\end{array}$ & $\begin{array}{c}81,51 \% \\
86,96 \% \\
84,73 \%\end{array}$ & $85,76 \%$ \\
\hline $\mathrm{CNN}$ & $\begin{array}{l}\text { Gás } \\
\text { Eletricidade } \\
\text { Água }\end{array}$ & $\begin{array}{c}7044 \\
29028 \\
3043\end{array}$ & $\begin{array}{c}7558 \\
29474 \\
3150\end{array}$ & $\begin{array}{c}93,2 \% \\
98,48 \% \\
96,6 \%\end{array}$ & $97,34 \%$ \\
\hline
\end{tabular}

- Detecção de marcador de dígito decimal vermelho;

- Pré-processamento (filtragem, remoção de ruído, remoção de reflexão superexposta, equalização de histograma);

- Limiar adaptativo (método de Otsu e limiar de Sauvola);

- Processamento de imagem binarizado (morfologia matemática, preservação de topologia de afinamento);

- Detecção de componentes conectados;

- Filtragem de componentes conectados e extração de dígitos;

- Normalização do tamanho dos dígitos.

No segundo estágio do método automático de leitura de medidores, os componentes conectados, encontrados nas imagens, são classificados com base em um conjunto de recursos extraídos. A abordagem usada é baseada em CNN que extrai hierarquicamente recursos através de filtros auto-aprendidos (Cerman et al., 2016).

De acordo com Cerman et al. (2016) para realizar o treinamento da CNN é necessário usar algumas milhares de imagens, em torno de 5000 imagens binárias de dígitos obtidas dos dígitos do medidor. A seguir usa-se transformações geométricas adicionais e morfologia matemática, para aumentar artificialmente o tamanho do conjunto de treinamento para cerca de 6 milhões de imagens. As transformações geométricas incluem pequenas rotações e translações, transformações de perspectiva e dimensionamento, para que o dígito esteja sempre totalmente exibido dentro da imagem sem cortes e há pelo menos um preenchimento de 2 pixels de cada lado. O mesmo se aplica às imagens morfologicamente transformadas depois de realizar erosão e dilatação. Cada imagem pode ter no máximo 3 operações aplicadas a ele ao mesmo tempo. Dessa forma, o conjunto de treinamento é artificialmente aprimorado, para neutralizar o sobreajuste e conter variação suficiente, potencialmente durante o processo de digitalização do medidor.

Para cada tipo de medidor da CEB e CAESB foi necessário obter pelo menos 5 mil imagens dos dígitos da leitura para efetuar o treinamento do reconhecimento dos dígitos (OCR). Estas imagens são usadas para a realização do treinamento do OCR, incluindo o novo medidor no banco de dados do kernel do OCR baseado em Rede Neural Convolucional, que é então disponibilizado em uma nova versão do kernel OCR, que será utilizado para o desenvolvimento do App.

Segundo Cerman et al. (2016) o índice de acerto mé- dio do método baseado em Rede Neural Convolucional é de $97,34 \%$ e baseado no método Tesseract é de $85,76 \%$. A Tabela 2 apresenta os resultados obtidos nesta análise comparativa (Cerman et al., 2016).

\section{Modelagem UML (Unified Modeling Lan- guage) da App}

Para o desenvolvimento do SIMAE (Sistema Inteligente de Medição de Água e Eletricidade) via App utilizase de um kernel de OCR usando técnicas de sistemas inteligentes (Rede Neural Convolucional) para realizar o reconhecimento de dígitos (Cerman et al., 2016), sendo capaz de realizar a leitura dos dígitos de um medidor de água/eletricidade/gás com indicação analógica ou digital.

Utiliza-se de Aprendizagem de Máquina, Deep Learning, com o uso de Rede Neural Convolucional para realizar o treinamento de milhares de imagens dos dígitos dos medidores. Foi construída uma bancada de teste para a captura de imagens de hidrômetros usados no DF (https://tinyurl.com/v97cr2u e https://tinyurl. com/thp87ze), podendo visualizar as imagens do visor do hidrômetro on-line (http://medicaohidrometro. alvarestech.com).

\subsection{Arquitetura do SIMAE}

A Fig. 2 apresenta a arquitetura concebida da aplicação móvel (App) para realizar a automação da leitura de medidores de água e eletricidade. A arquitetura foi denominada de SIMAE (Sistema Inteligente de Medição de Água e Eletricidade) baseada em visão computacional.

Para equacionar a solução do problema descrito, foi desenvolvido um sistema generalizado de leitura de dígitos denominado de AppMedidor (Fig. 2). O sistema foi implementado para plataforma Android e iOS sendo capaz de realizar a aquisição de dados, leitura dos dígitos, a partir de visão computacional usando o kernel OCR baseado em Rede Neural convolucional, realizando o armazenamento do valor medido reconhecido através do OCR, time stamp (data/hora medição), código de barras ou QR com identificação do medidor (Id se presente) e da imagem adquirida, em dois bancos de dados: sendo um local no próprio dispositivo móvel (SQLite, banco de dados SQL); e outro em nuvem (Firebase, banco de dados NoSQL). O histórico de leituras armazenadas localmente e em nuvem pode ser visualizado através da App. 


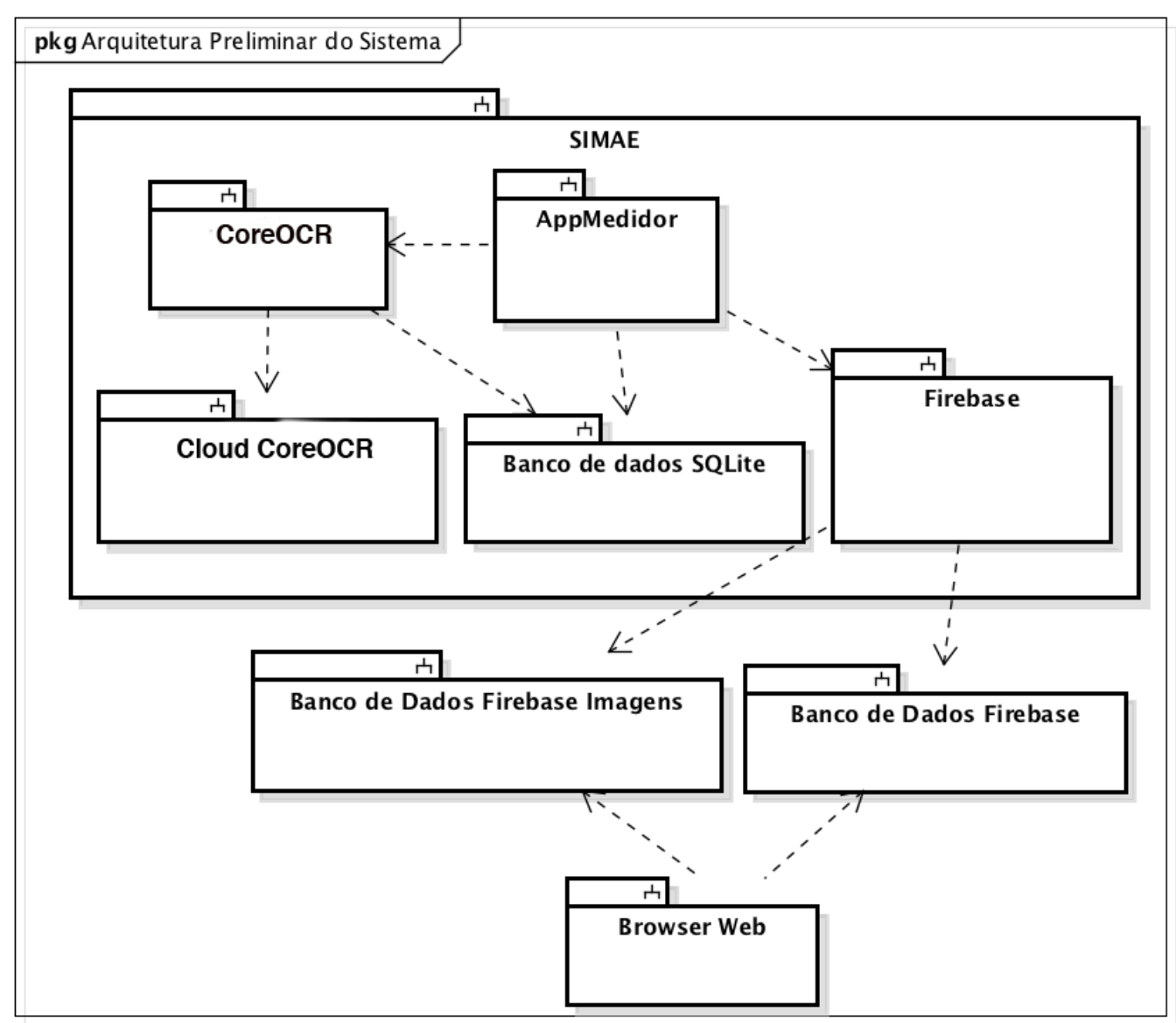

Figura 2: Arquitetura do SIMAE (Sistema Inteligente de Medição de Água e Eletricidade) em Diagrama UML de subsistemas

\subsection{Requisitos de Usuário}

Os requisitos de usuário são divididos em requisitos funcionais e requisitos não funcionais, sendo apresentados em duas listas, nas subseções seguintes.

\subsubsection{Requisitos Funcionais}

- Requisito FU1: o sistema deve permitir o cadastramento do usuário, bem como a edição de seus dados e recuperação de senha na nuvem, Firebase;

- Requisito FU2: o sistema deve realizar a leitura automatizada dos dígitos do medidor com processamento local, no dispositivo móvel (celular/tablet), realizado pelo App;

- Requisito FU3: o sistema deve permitir a obtenção da identificação do medidor através de código de barras/QR se presente no medidor com processamento local, no dispositivo móvel, realizado pelo App;

- Requisito FU4: o sistema deve armazenar os dados da leitura, da imagem, time stamp (data/hora), latitude/longitude, código de barras/QR do medidor no banco de dados local, no dispositivo móvel, via SQLite;

- Requisito FU5: o sistema deve armazenar os dados da leitura, da imagem, time stamp (data/hora), có- digo de barras/QR do medidor no banco de dados em nuvem, Firebase;

- Requisito FU6: o sistema deve apresentar na própria App o histórico dos dados armazenados no SQLite (histórico local);

- Requisito FU7: o sistema deve apresentar na própria App o histórico dos dados armazenados no Firebase (histórico remoto, na nuvem);

- Requisito FU8: o sistema deve preservar os dados obtidos pela leitura, em caso de perda da conexão ao Firebase via Internet, e assim que for restabelecida deverá armazenar os dados na nuvem, de forma transparente ao usuário, desde que o usuário esteja conectado ao App, acesso validado via login/password na nuvem, com acesso às funcionalidades do aplicativo, antes da perda da conexão ao Firebase.

\subsubsection{Requisitos Não-Funcionais}

- Requisito N-FU1: o sistema deve estar aderente às necessidades das empresas concessionárias de eletricidade e água do Distrito Federal (CEB e CAESB), podendo também ser utilizado por outras empresas do Brasil com os devidos ajustes e particularidades de cada empresa; 


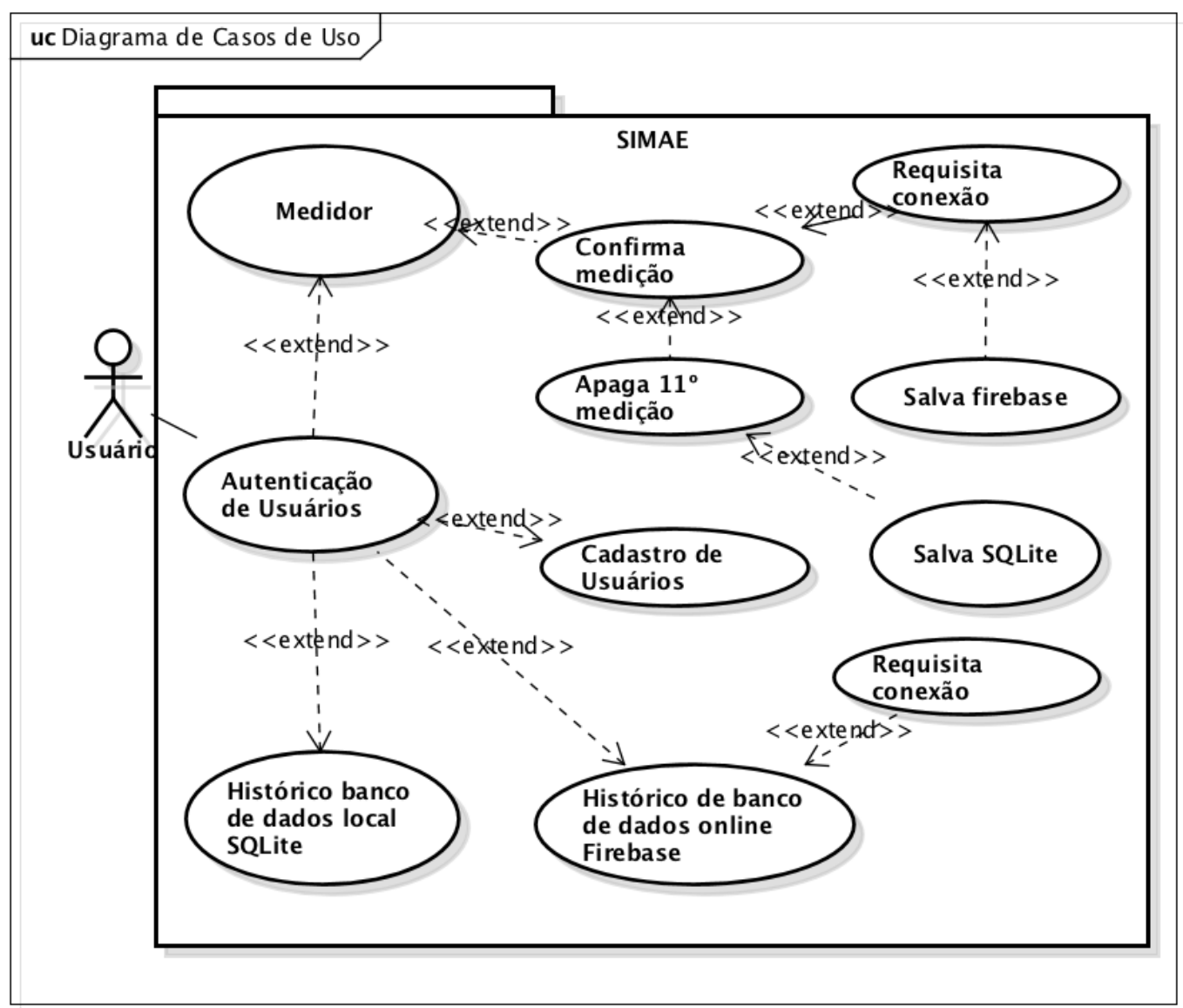

Figura 3: Casos de Uso do SIMAE (Sistema Inteligente de Medição de Água e Eletricidade) em Diagrama UML de Casos de Uso

- Requisito N-FU2: o sistema deve ser desenvolvido para plataformas móveis Android e iOS;

- Requisito N-FU3: o sistema deve utilizar Rede Neural Convolucional;

- Requisito N-FU3: o sistema deve prever o aprendizado de máquina para realizar reconhecimento de dígitos de outros medidores não testados;

- Requisito N-FU4: O sistema deve ser escalonável podendo ter milhões de usuários;

- Requisito N-FU5: o sistema deve prever integração futura com ambiente de Análise Preditiva em servidor na nuvem, como a plataforma Watson da IBM;

- Requisito N-FU6: o sistema deve permitir o acesso aos dados armazenados em nuvem via Web/navegador.

\subsection{Casos de Uso}

A Fig. 3 apresenta o diagrama de Casos de Uso correspondente ao usuário da App (aplicação). O usuário poderá, após autenticação que permite acesso à App, realizar a medição usando visão computacional (OCR), ou realizar a consulta de históricos de medição armazenado localmente (SQLite Celular)) e/ou visualizar o histórico armazenado em nuvem (Firebase).

\section{Estudo de Caso: App CAESB e App CEB}

Foram desenvolvidas duas App, uma para CAESB e outra para CEB. Foram criados dois bancos de dados Firebase: banco de dados caesbmeter (medidores de água) e banco de dados cebmeter (medidores de eletricidade).

São apresentados como resultados dois estudos de casos sobre a aplicação das Apps, um para medição de eletricidade e outro para medição de água. Os medidores são das empresas CEB e CAESB, sendo escolhido um medidor com indicação digital para CEB e um medidor com indicação analógica para CAESB. Por fim é apresentado o banco de dados NoSQL em nuvem, Firebase, que armazena as leituras, imagens, time stamp, latitude/longitude e Id do medidor (código de barras/QR).

\subsection{Medidores de Eletricidade - Relógio de Luz CEB}

A Fig. 4(a) apresenta a tela de solicitação de medição, onde temos três atividades: Realizar Medição; Histórico Local de Medições; Histórico Remoto de Medições.

O fluxo de atividades consiste em apertar o botão Realizar Medição, o que executa uma nova atividade associada ao OCR, visão computacional, onde é feita 

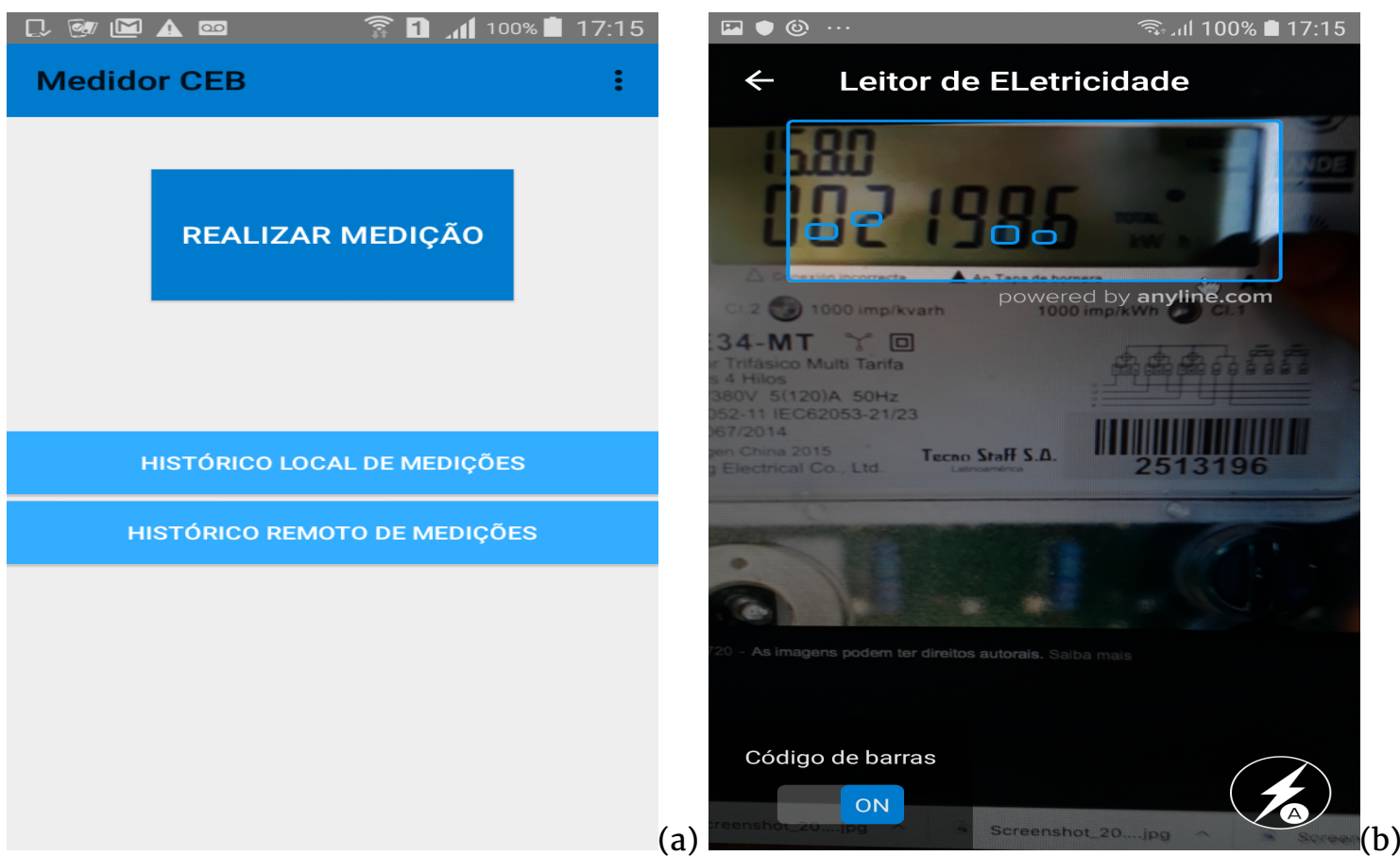

Figura 4: Telas App leitura automática de consumo de eletricidade (Relógio de Luz CEB com indicação digital)

a leitura do medidor, podendo também fazer a leitura de Código de Barras/QR caso o medidor tenha uma identificação, conforme mostrado na Fig. 4(b).

A Fig. 5(a) apresenta o Resultado da Medição obtido pela atividade Realizar Medição (Fig. 4(b)), onde o OCR faz a detecção de dígitos do medidor com indicação digital, bem como realiza a leitura do código de barras ou do código QR. Caso a detecção dos dígitos esteja correta, é necessário apertar o botão CONFIRMAR, se estiver errado pode voltar à tela anterior através do botão SETA. Após confirmação da leitura, o OCR é novamente ativado voltando para tela de medição (Fig. 4(b)), podendo realizar nova medição da leitura dos dígitos de forma automática.

A Fig. 5(b) apresenta o Histórico Remoto de medição armazenado no banco de dados Firebase em nuvem, onde foi selecionada a data desejada, 26-06-2019, em um calendário (ano, mês e dia) e as medições realizadas no dia são apresentadas fazendo o download das imagens e apresentando também o valor da leitura, Id medidor e time stamp. Um vídeo da App CEB (relógio de luz com indicação digital) é apresentado na URL https://tinyurl.com/y289haqd.

\subsection{Medidores de Água - Hidrômetro CAESB}

De forma similar ao caso anterior, a Fig. 6(a) apresenta a tela de solicitação de medição, tendo as três atividades descritas anteriormente. O fluxo de atividades é similar ao caso anterior, e o processo OCR é mostrado na Fig. 6(b).

De forma similar, a Fig. 7(a) apresenta o Resultado da Medição obtido pela atividade Realizar Medição
(Fig. 6(b)), onde o OCR faz a detecção de dígitos do medidor com indicação analógica, bem como realiza a leitura do código de barras/QR.

A Fig. 7(b) apresenta o Histórico local de medição, armazenado no banco de dados SQLite no aparelho móvel do usuário, onde pode ser visto as ultimas leituras obtidas, apresentando o valor da leitura, time stamp, Id medidor e imagem do medidor. A imagem do medidor pode ser usada como prova da leitura realizada. As URL https://tinyurl.com/y5q6m9d4 e https://tinyurl.com/yyaftrhz demonstram o uso da App CAESB (hidrômetro com indicação analógica).

\subsection{Banco de Dados na Nuvem: Firebase}

O banco de dados NoSQL Firebase possui na realidade dois ambientes de armazenamento: um para dados e outro para imagens. Os dados de Autenticação dos usuários cadastrados no sistema Firebase estão aramazenados na base de dados Authentication. O Realtime Database, do Firebase, armazena os dados cadastrais do usuário e as leituras por data e hora.

As leituras armazenadas no Firebase, nuvem, serão processadas futuramente visando uma análise preditiva para gestão do recurso hídrico ou de eletricidade por parte da concessionária, bem como, a publicação de notificação para App do usuário visando a gestão do uso do recurso, água ou energia elétrica. Este artigo não irá tratar da análise preditiva. O Storage do Firebase armazena para cada usuário (CPF/CNPJ/Email) e para uma data específica as imagens adquiridas pelo OCR.

$O$ Firebase pode ser acessado via Web/navegador conforme Fig. 8, onde é feita a consulta ao banco de dados 

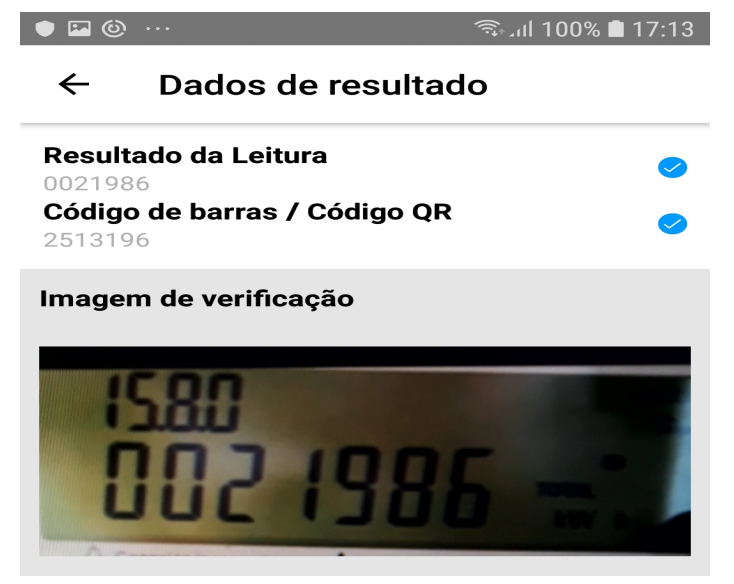

CONFIRMAR

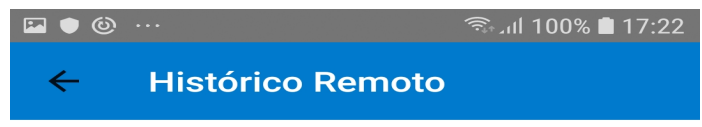

\section{Leituras encontradas na Data 28-06-2019}

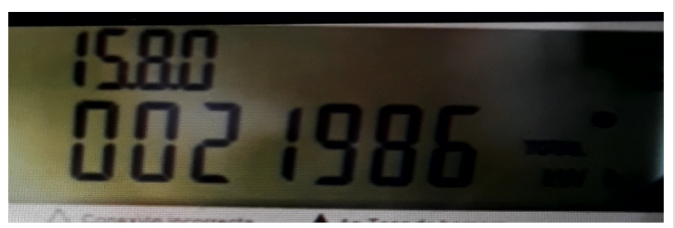

Hora: 17:05:33

Valor Lido: 0021986

Código Barras/QR: 2513196

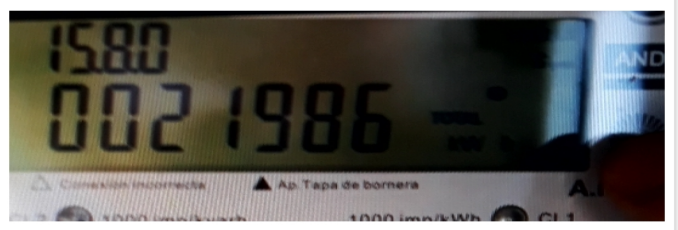

(b)

Figura 5: Telas App leitura automática de consumo da CEB - Resultado Medição e Histórico Remoto

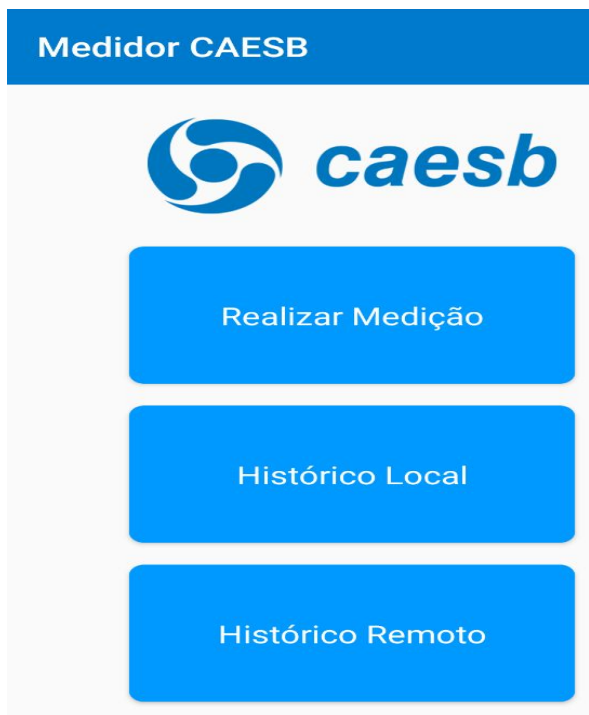

$\vdots$

(a)

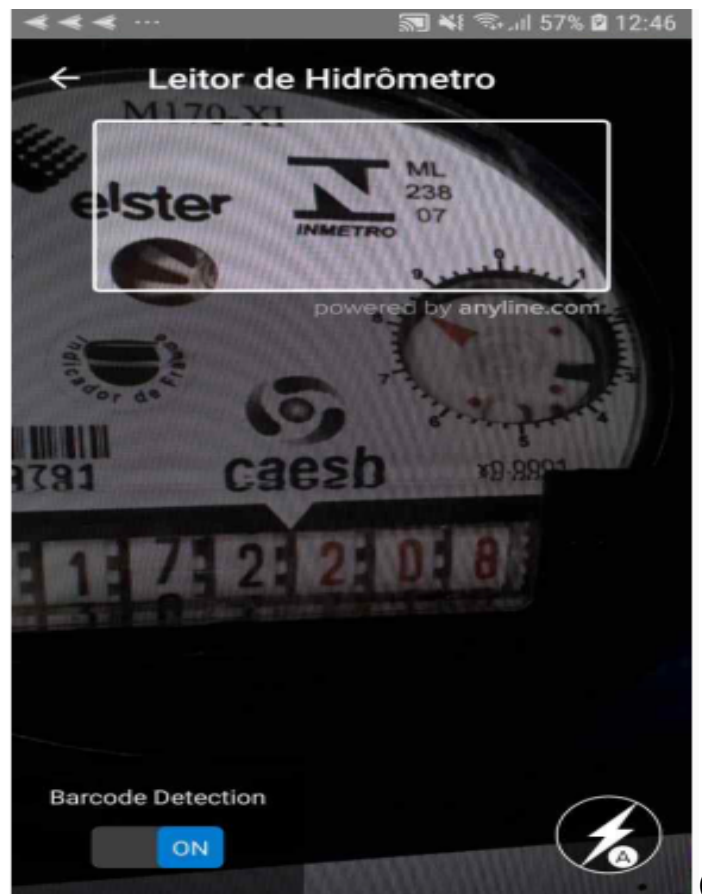

(b)

Figura 6: Telas App leitura automática de consumo de água (Hidrômetro com indicação analógica).

Storage (módulo Firebase), apresentado as imagens armazenadas. Para integrar o Firebase com as API Watson da IBM será utiizado o orquestrador Node-RED (Ngu et al., 2017, Wilson, 2018).

\section{Conclusão}

O método proposto foi patenteado (Alvares, 2017), visando a automação da leitura de medição de medidores analógicos baseado em visão computacional e apren- 


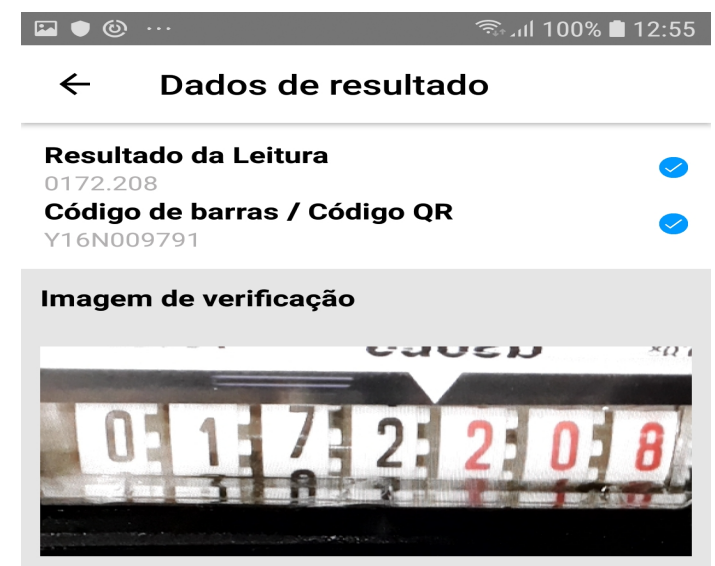

CONFIRMAR

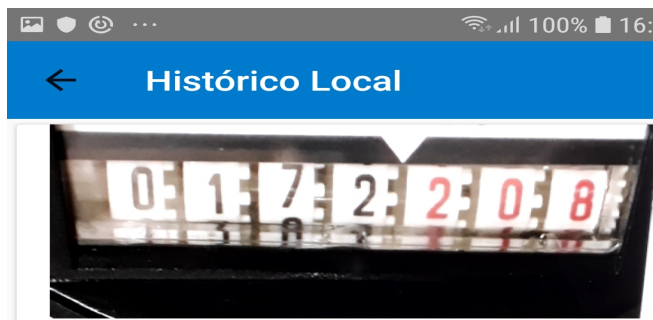

Data: 28-06-2019 as 16:39:04 Valor: 0172.208

QR Code: Y16N009791

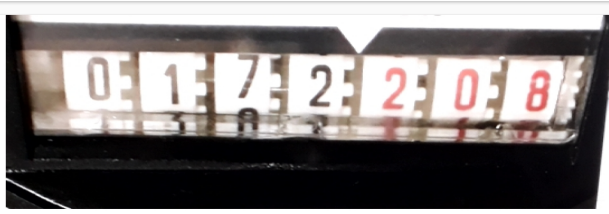

Data: 28-06-2019 as 16:39:01 Valor: 0172.208

QR Code: Y16N009791

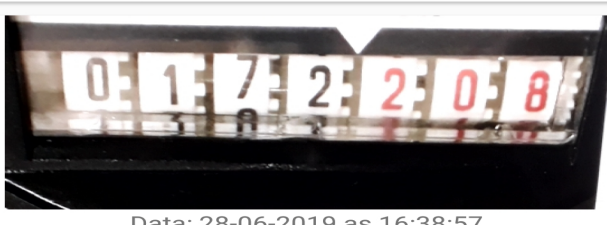

(b)

Figura 7: Telas App leitura automática de consumo de água - Resultado Medição e Histórico Local

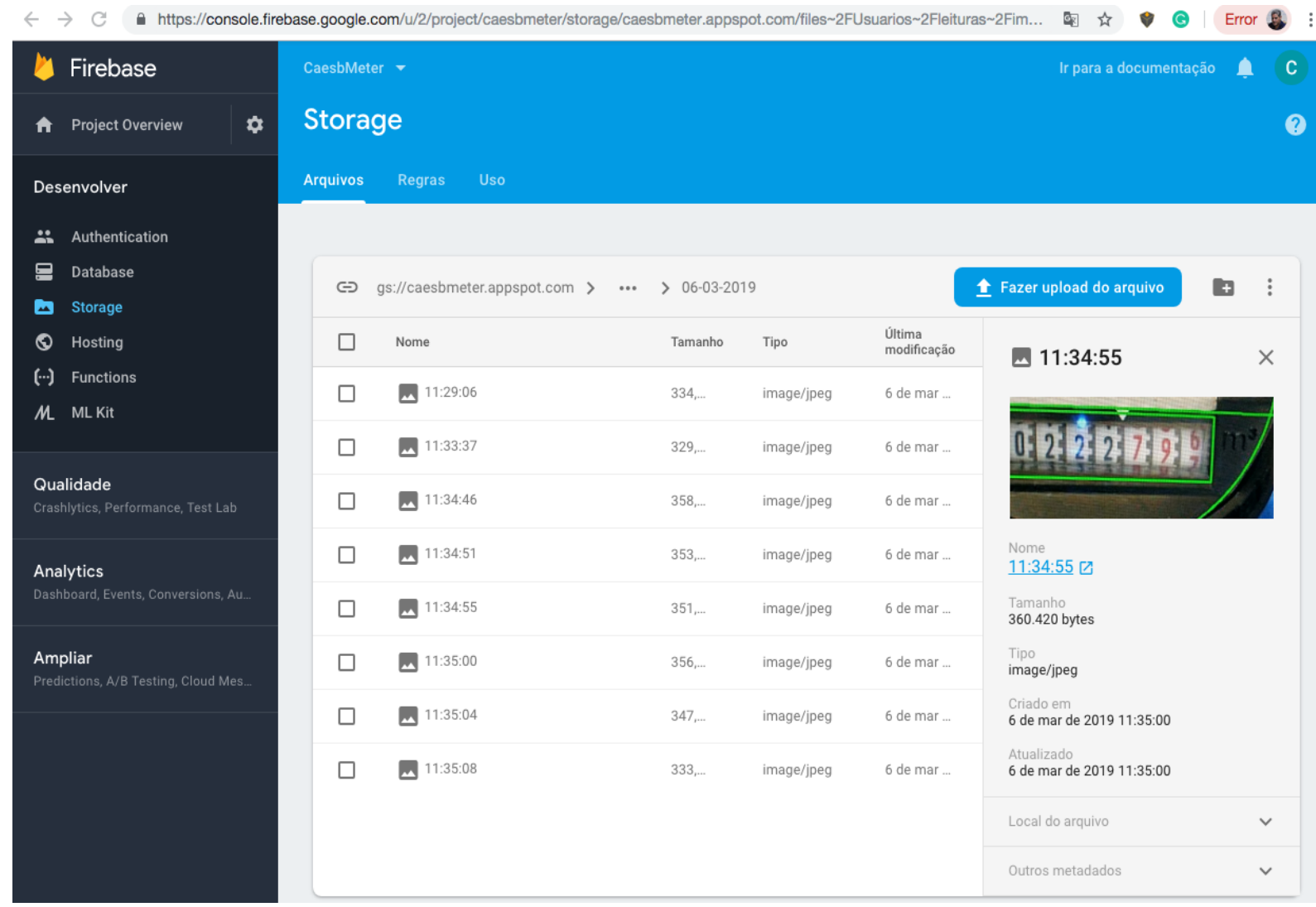

Figura 8: Módulo Storage do banco de dados NoSQL Firebase da CAESB 
dizagem de máquina, pois tem grande potencial de produto de mercado por ser o primeiro em desenvolvimento no Brasil e que poderá ser um produto de ruptura no mercado de leitura de medidores de água, eletricidade e gás no Brasil, pois temos mais de 40 milhões só de hidrômetros, sendo um mercado estimado de mais de 400 milhões de reais anuais associados à leitura manual de hidrômetros no Brasil (leiturista).

A solução é escalonável podendo atender todo o universo de medidores de água, eletricidade e gás no Brasil, podendo ser uma família de Apps usadas por toda a população brasileira fazendo uma gestão mais racional dos seus medidores, centrada no usuário, gerando leituras uma ou mais vezes por dia, o que irá permitir uma gestão sustentável do uso e distribuição de água em todo o Brasil, tendo um impacto significativo na eficiência das empresas de distribuição de água que poderão diminuir as perdas em seu sistema de distribuição de água, por ter dados de consumo diário do consumidor final, permitindo uma ganho significativo e diminuindo as perdas de $34,49 \%$ (2018) para $12 \%$, como no caso da CAESB.

O maior beneficiário do uso da App, no contexto da Internet dos Hidrômetros, por todos o consumidores será a própria sociedade, pois irá permitir uma gestão eficiente e sustentável do uso e distribuição de água, por exemplo, permitindo uma significativa diminuição do desperdício de água.

Com uma boa estratégia de gestão da Internet dos Hidrômetros, quando se tem dados diários de consumo de cada cliente final, será possível detectar vazamentos em um curto espaço de tempo e comunicar o cliente final, por exemplo via SMS, que evitará desperdício de água, diminuição do nível dos reservatórios e diminuição do valor da conta por detectar rapidamente os vazamentos.

Com o uso desta tecnologia disruptiva a medição manual, mesmo tendo baixo custo do leiturista para fins de faturamento da conta, quando comparado ao uso de medidores inteligentes, não mais se justifica, pois o processo digitalizado centrado no cliente com uso de App é muito mais eficiente e tem menor custo que o processo manual.

No modelo usado pelas empresas, atualmente, baseado em leitura manual é impossível fazer uma gestão dos dados da medição com a finalidade de detectar vazamentos, ligações ilegais ou fraudes de energia elétrica.

Se a medição for em tempo real (medidor inteligente) ou várias vezes por dia, pode-se diminuir o consumo de água e energia elétrica com a gestão inteligente usando o conceito de Internet do Hidrômetros ou Internet dos Relógios de Luz, ou de qualquer outro medidor analógico que possa ser monitorado e conectado à Internet das Coisas, usando o método de automatização da leitura e publicando os dados pelo menos uma vez por dia via App.

As Apps já estão desenvolvidas, plataformas Android e iOS, e no momento as ações ocorrem em duas direções. A primeira visa disponibilizar as Apps com apoio da CEB e CAESB para o usuário final através de uma empresa Startup chamada Smart Telemetria (http://SmartTelemetria.com). A segunda visa o desen- volvimento de um sistema de análise dos dados em nuvem usando a plataforma IBM Watson (APIs) para realizar as notificações para o usuário visando o uso eficiente do recurso usando técnicas associadas à Big Data Analytics.

\section{Agradecimentos}

Os autores agradecem o apoio da FAPDF/CAPES/CNPq e das empresas CAESB/CEB.

\section{Referências}

Alcácer, V. and Cruz-Machado, V. (2019). Scanning the industry 4.0: A literature review on technologies for manufacturing systems, Engineering Science and Technology, an International Journal 22(3): 899 - 919. https://doi.org/10.1016/j. jestch.2019.01.006.

Alvares, A. J. (2017). Método para leitura de medidores de consumo de Água (hidrômetros), de energia (relógio de luz), de gás (relógio de gás) e outros usando visão computacional e aprendizagem de máquina em dispositivos móveis, smartphones e tablets, com uso de app. INPI BR10201702865.

Alvares, A. J. and Santiago, G. V. (2020). Deployment framework for the internet of water meters using computer vision on arm platform, Journal of Ambient Intelligence and Smart Environments 12(1): 35-60. http: //dx.doi.org/10.3233/AIS-200544.

Alvisi, S., Casellato, F., Franchini, M., Govoni, M., Luciani, C., Poltronieri, F., Riberto, G., Stefanelli, C. and Tortonesi, M. (2019). Wireless middleware solutions for smart water metering, Sensors (Basel, Switzerland) 19(8): 1853. http://dx.doi.org/10.3390/s19081853.

Auerswald, E. (2017). Seven segment optical character recognition. Disponível em https://www. unix-ag. uni-kl.de/ auerswal/ssocr/.

Bae, K. S., Kim, K. K., Chung, Y. G. and Yu, W. P. (2005). Character recognition system for cellular phone with camera, 29th Annual International Computer Software and Applications Conference (COMPSAC'O5), Vol. 1, pp. 539-544 Vol. 2. https://doi.org/10.1109/ COMPSAC. 2005. 55.

CAESB (2019). Relatório de indicadores de desempenho caesb 2019. Disponível em https://tinyurl.com/ r7w8kae.

Cerman, M., Shalunts, G. and Albertini, D. (2016). A mobile recofnition system for analog energy meter scanning, Advances in Visual Computing - 12th International Symposium, ISVC 2016, Las Vegas, NV, USA, December 12-14, 2016, Proceedings, Part I, pp. 247-256. https://doi.org/10.1007/978-3-319-50835-1_23.

Chouiten, M. and Schaeffer, P. (2014). Vision based mobile gas-meter reading, Scientific Cooperations International Workshops on Electrical and Computer Engineering Subfields, pp. 94-97. Disponível em http: //conf-scoop.org/ACV-2014/8.M.Chouiten_ACV.pdf. 
Elrefaei, L. A., Bajaber, A., Natheir, S., AbuSanab, N. and Bazi, M. (2015). Automatic electricity meter reading based on image processing, 2015 IEEE Jordan Conference on Applied Electrical Engineering and Computing Technologies (AEECT), pp. 1-5. https://doi.org/ 10.1109/AEECT . 2015.7360571.

Gallo, I., Zamberletti, A. and Noce, L. (2015). Robust angle invariant GAS meter reading, 2015 International Conference on Digital Image Computing: Techniques and Applications (DICTA), IEEE. https://doi.org/10.1109/ dicta.2015.7371300.

Kompf, M. (2013). Opencv practice: Ocr for the electricity meter. Disponível em https://www.mkompf.com/ cplus/emeocv.html.

LeCun, Y., Bengio, Y. and Hinton, G. (2015). Deep learning, Nature 521(7553): 436-444. http://dx.doi. org/10.1038/nature14539.

Mendes, P. R. C., Rocha, C. V. M., Paiva, A. M. P. and dos Santos, J. M. (2020). Reconhecimento de dígitos de medidores de energia por meio da voz no contexto de um aplicativo de autoleitura, Brazilian Applied Science Review 4(3): 1976-1989. http: //dx.doi.org/10.34115/basrv4n3-098.

Nardo, A. D., Natale, M. D. and Mauro, A. D. (2013). Water Supply Network District Metering: Theory and Case Study, CISM International Centre for Mechanical Sciences, 1 edn, Springer-Verlag Wien. http://dx.doi . org/10.1007/978-3-7091-1493-3.

Ngu, A. H., Gutierrez, M., Metsis, V., Nepal, S. and Sheng, Q. Z. (2017). Iot middleware: A survey on issues and enabling technologies, IEEE Internet of Things Journal 4(1): 1-20. http://dx.doi.org/10.1109/JIOT. 2016.2615180 .

Oliveira, L. C. P. L. (2013). Maquinagem de superfícies complexas com recurso a sistema robótico, Master's thesis, Universidade do Porto.

Pattinson, C. (2015). Chapter 2 - Emerging Technologies and Their Environmental Impact, Morgan Kaufmann, Boston. https://doi.org/10.1016/ B978-0-12-801379-3.00002-4.

Pelandiana, A. L. and Ado, R. G. (2018). Web-based billing and collection system for a municipal water and services unit, 4th International Research Conference on Higher Education, KnE Social Sciences, p. 1-30. https://doi.org/10.18502/kss.v3i6.2371.

Puttnies, H., Altmann, V., Golatowski, F. and Timmermann, D. (2015). Cost-efficient universal approach for remote meter reading using web services and computer vision, 2015 IEEE 16th International Symposium on A World of Wireless, Mobile and Multimedia Networks (WoWMoM), IEEE. https://doi.org/10. 1109/wowmom. 2015.7158205.

Rayes, A. and Samer, S. (2016). Internet of Things From Hype to Reality: The Road to Digitization, Springer. https://doi .org/10.1007/978-3-319-44860-2.

Santiago, G. V. and Alvares, A. J. (2017). Método Baseado em Visão Computacional Para Reconhecimento de Dígitos
Visando a Leitura De Consumo em Hidrômetros Com Indicação Analógica E Digital, Universidade de Brasilia. Trabalho de Conclusão de Curso em Engenharia Mecatrônica.

Seneviratne, P. (2019). Beginning LoRa Radio Networks with Arduino: Build Long Range, Low Power Wireless IoT Networks, Technology in Action, 1 edn, Apress.

Smith, R. (2007). An overview of the tesseract ocr engine, Ninth International Conference on Document Analysis and Recognition (ICDAR 2007), Vol. 2, pp. 629633. https://doi.org/10.1109/ICDAR.2007.4376991.

Sonali, T., Vrushali, V., Shobha, N. and Nayan, C. (2015). Android based meter reading using ocr, CInternational Journal for Research in Engineering Application and Management 2(4): 631-635. Disponível em http://www.mjret.in/V2I4/M1-2-4-10-2015.pdf.

Spichkova, M., van Zyl, J., Sachdev, S., Bhardwaj, A. and Desai, N. (2019). Easy mobile meter reading for non-smart meters: Comparison of aws rekognition and google cloud vision approaches, ENASE 2019, SCITEPRESS - Science and Technology Publications, Lda, Setubal, PRT, p. 179-188. https://doi.org/10. 5220/0007762301790188.

Sun, Q., Li, H., Ma, Z., Wang, C., Campillo, J., Zhang, Q., Wallin, F. and Guo, J. (2016). A comprehensive review of smart energy meters in intelligent energy networks, IEEE Internet of Things Journal 3(4): 464479. https://doi.org/10.1109/JIOT. 2015. 2512325.

Tafti, A. P., Baghaie, A., Assefi, M., Arabnia, H. R., Yu, Z., and Peissig, P. (2016). Ocr as a service: An experimental evaluation of google docs ocr, tesseract, abbyy finereader, and transym, Advances in Visual Computing - 12th International Symposium, ISVC 2016, Las Vegas, NV, USA, December 12-14, 2016, Proceedings, Part I, pp. 735746. https://doi .org/10.1007/978-3-319-50835-1.

Toledo, F. (2013). Smart Metering Handbook, Vol. 1 of 1 , 1 edn, Pennwell Pub.

Vanetti, M., Gallo, I. and Nodari, A. (2013). Gas meter reading from real world images using a multi-net system, Pattern Recognition Letters 34(5): 519 - 526. https://doi.org/10.1016/j.patrec. 2012.11.014.

Weranga, K. S. K., Kumarawadu, S. and Chandima, D. P. (2014). Smart Metering Design and Applications, SpringerBriefs in Applied Sciences and Technology, 1 edn, Springer-Verlag Singapur. http://dx.doi.org/ 10.1007/978-981-4451-82-6.

Wilson, J. (2018). Node.js 8 the Right Way: Practical, Server-Side JavaScript That Scales, 1 edn, Pragmatic Bookshelf.

Zhao, S., Li, B., Yuan, J. and Cui, G. (2005). Research on remote meter automatic reading based on computer vision, 2005 IEEE/PES Transmission Distribution Conference Exposition: Asia and Pacific, pp. 1-4. https://doi.org/10.1109/TDC. 2005.1546972. 